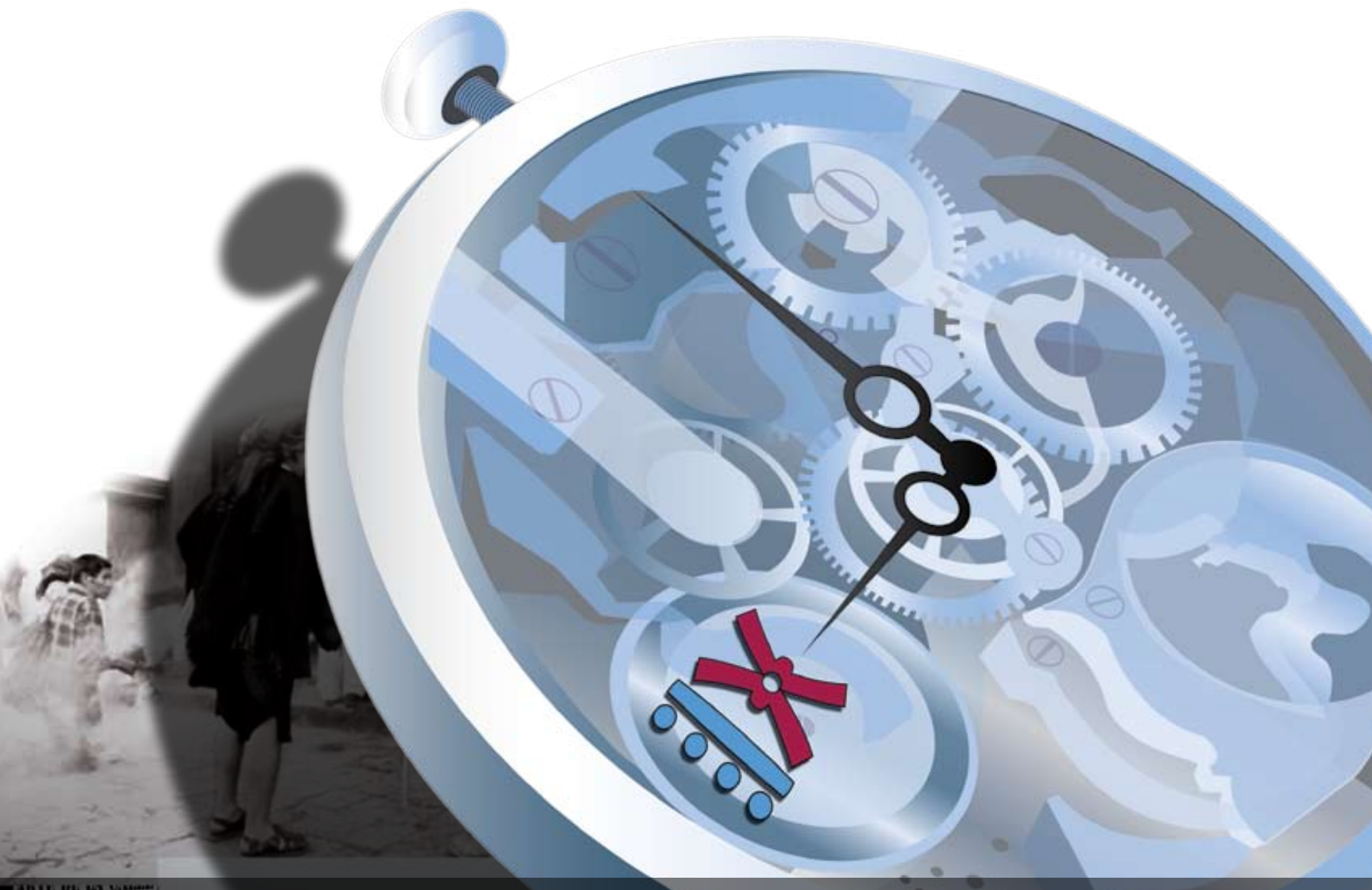

$9^{\circ}$ C O N G R E S O 2. CENTROAMERICANO DE H ISTO R I A

Universidad de Costa Rica

ISSN 1409- 469X

Fecha de recepción: 15 de mayo 2008 Fecha de aceptación: 30 de mayo 2008

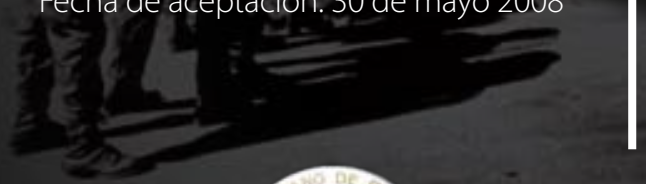

La influencia anglosajona en el caribe de Costa Rica. Finales S. XIX-primera mitad S. XX.

Miembros del Consejo Editorial:

Dr. Ronny Viales, Dr. Juan José Marín

Editores Técnicos:

Allan Fonseca, Andrés Cruz, Gabriela Soto.
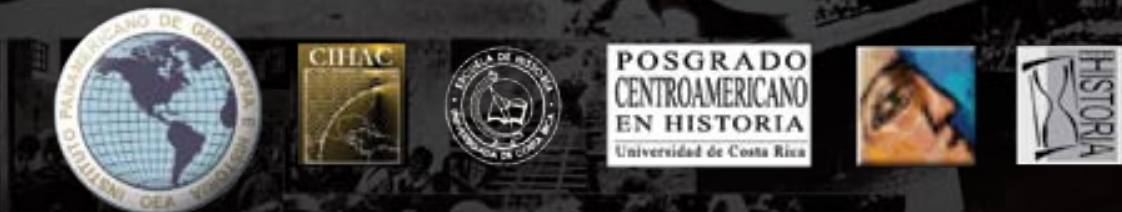
Indexaciones: Repositorio de Revistas UCR, DIALNET, Latindex, REDALYC Directorio y recolector de recursos digitales del Ministerio de Cultura de España, Directory of Open Access Journals. Diálogos Revista Electrónica de Historia ISSN 1409-469X. Número especial 2008. Dirección web: http://historia.fcs.ucr.ac.cr/dialogos.htm

\section{La influencia anglosajona en el caribe de Costa Rica. Finales S. XIX- primera mitad S. XX.}

Dr. Enrique Zapata D.

Lic. Gerardo Meza S.

Profesores de la Universidad de Costa Rica 


\section{EL CARIBE DE COSTA RICA}

Costa Rica, pequeño país ubicado en el extremo sur de la América Central, se supone que debe su nombre a la riqueza natural que observaron los españoles a la llegada a sus costas durante el cuarto viaje que Cristóbal Colón realizó a las Américas en 1502. Cuando el Almirante Cristóbal Colón arribó a las costas del Caribe costarricense al mediodía del 25 de septiembre de 1502 fondeo en la isleta denominada por los nativos como Quiribirí frente a un pueblo llamado Cariay. Por la frondosidad y rica flora de la isleta el Almirante la llamo la Huerta, pero posteriormente pasaría a llamarse La Uvita. El sitio ubicado frente a la isleta luego sería denominado Limón en honor al único limonero que había en toda la zona. Este nombre aparece oficialmente a partir de octubre de 1852 cuando a través de un decreto se habilita el puerto, lugar que paso a denominarse oficialmente Puerto Limón (González, 1999:302-303; Azofeifa, 1986:121). Sin embargo, en uno de los escritos de León Fernández, según Eduardo Azofeifa, aparece información interesante sobre un personaje llamado Miguel de Limón, hijo de un tal Pablo Limón, oriundo de Puerto Llano, quien emigra de España en 1575, lo cual a todas luces, pareciera ser, es mera coincidencia pues sería demasiada remota la posibilidad de que el nombre del cantón de esta región caribeña de Costa Rica proceda de ese personaje, lo que no desmerece hacer aquí su mención.

Durante la Colonia, la región del Caribe costarricense se caracterizó por su escasa población, inaccesibilidad e inclemencias propias de la naturaleza tales como clima e insalubridad, condiciones propias del trópico inmensamente húmedo. Eran tiempos cuando los piratas ingleses asolaban la región del Caribe y campeaba el tráfico ilegal de mercancías y personas. Después de la independencia, el Estado trata de establecer alguna presencia en la región pero no es sino a partir de 1870 en que la burguesía liberal impulsa la colonización de esa parte del país básicamente alrededor del proyecto de construcción del ferrocarril y de la apertura de un puerto para exportar café. En 1871 y 1872 son trazadas las 50 "manzanas" ("cuadras" o "blocks" en inglés) que dieron origen a la nueva ciudad, alrededor de la cual se impulso el desarrollo de toda la región, en primer lugar la construcción de los muelles y del ferrocarril. Al nuevo Puerto Limón arribaron inmigrantes de las más diversas procedencias quienes en un principio se establecieron en la nueva ciudad, mientras que otros se internaron tierra adentro en busca de mejores oportunidades. 
En Puerto Limón florecieron el comercio y el contrabando; su cosmopolitismo hizo que su vida se diferenciara de la del resto del país: se hablan en diferentes idiomas, en las calles se venden los más variados platillos y comidas extranjeras y los lugareños tienen la posibilidad de asistir ya sea a una iglesia protestante, a un billar o a uno de los tantos establecimientos de licor que ya por aquella época existían en gran cantidad y en donde, a diario se bailaba al son de tambores y cajones hasta altas horas de la madrugada (Murillo, 1995:54).

Para la segunda mitad del siglo XIX, las necesidades de la naciente burguesía agraria y del Estado liberal por sacar al exterior los productos como el café, le hace necesaria la construcción del ferrocarril hacia las costas del Caribe costarricense y la construcción de la infraestructura portuaria necesaria para tal fin. Por las condiciones geográficas, el lugar ideal para la construcción de muelles se centró en lo que hoy conocemos como Puerto Limón.

La construcción del ferrocarril se convirtió en la obra de mayor envergadura de aquel entonces, obra que a su vez demandaba importantes contingentes humanos necesarios para la realización de la obra. Además, según el Tratado Soto-Keith, el Estado costarricense otorgó a este último la concesión de la obra por 99 años, se le otorgaron facilidades portuarias en Limón y 800 mil acres de tierras en el Caribe (Molina, 2002:58). En tal contexto los Keith fundan en Boston, en 1899, la United Fruit Company que se dedicaría a explotar las tierras concedidas para el cultivo de variedad de productos, primordialmente banano.

La construcción del ferrocarril hacia el Caribe y la explotación bananera a fines del siglo XIX cambió no solamente el panorama geográfico del Caribe costarricense, sino también la composición étnica de sus pobladores, lo que a su vez acarreo un radical cambio en las manifestaciones culturales de sus habitantes. Así, en el Caribe costarricense se establecieron habitantes de variadas razas y grupos étnicos que hablan su idioma o dialecto, tenían sus costumbres, comidas y creencias religiosas propias. Aborígenes, negros, chinos, indios, árabes, europeos y mestizos se mezclaron para constituir el ser limonense con su particular idiosincrasia que se diferenciaba de manera sustancial del resto de la población del país. Tal situación, a más de cien años de aquella incursión, aún se mantiene: Puerto Limón continua siendo centro de 
atracción y expulsión de enormes contingentes humanos procedentes tanto del interior del país como del exterior; es un original centro urbano que quiere ser ciudad-puerto abierto al mundo; su población está compuesta por un mosaico de razas que hablan su lengua, profesan su religión, tienen sus costumbres, ríen y lloran al son del tambor. Limón, Puerto Limón, se puede decir que continúa siendo un país dentro otro país, un enclave en el Caribe del país.

\section{PARTICULARIDADES DEL CARIBE COSTARRICENSE}

Con la provincia de Limón, Costa Rica se integra a una cadena étnica y cultural que abarca las regiones del Caribe centroamericano desde Guatemala y Belice hasta Panamá. En esta cadena se comparten elementos materiales y espirituales con el resto de las Antillas del Caribe insular, el Caribe colombiano y venezolano inclusive. Limón ha sido y es una provincia con características de gueto muy propias de la "periferia de la periferia". Esto debido a su posición geográfica, alejada del área metropolitana del país, con una geografía adversa, clima riguroso y deficientes vías de comunicación, así como por prejuicios relacionados con las diferencias de origen, raza, religión y lenguaje, por lo que se ha segregado a su población cayendo en algunas ocasiones en racismo solapado. Se puede decir que la particularidad de la región caribeña de Costa Rica, en mucho se asemeja a las particularidades de la misma índole que observamos en el corredor biológico y etno-cultural que discurre desde Venezuela y prácticamente hasta Nueva Orleáns.

Limón es una provincia en la que conviven indígenas, afro caribeños, centroamericanos, libaneses, indostaníes y chinos, junto a numerosos costarricenses venidos de diversas partes del interior. En la actualidad su población es una interesante mezcla de grupos étnicos que conforman un crisol de nacionalidades único en el país.

Su condición de enclave no le permitió a Limón iniciar el despegue económico que tuvo por ejemplo la región central del país, motivado entre otras razones porque las transnacionales bananeras y el ferrocarril no permitieron el surgimiento, desarrollo y consolidación de una burguesía local que pudiera competir y/o impulsar el desarrollo de la región. Tales condiciones 
propiciaron, por un lado, el total dominio de las transnacionales y por otro, la "castración" económica de lo que pudo ser una burguesía nacional-regional que marcará las pautas de desarrollo posterior de esta parte del país. Podemos, desde tal perspectiva, deducir que la proletarización de los habitantes del Caribe costarricense tuvo su génesis en este periodo de nuestra historia e influyó decididamente para que tales condiciones persistan hasta la actualidad, pues la inmensa mayoría de su población continúa siendo de asalariados dependientes de las empresas transnacionales ligadas a la explotación bananera y a las instituciones del Estado que a partir de la mitad del siglo XX ha incursionado en la región. Esta situación no difiere mucho del escenario que se vive en otras latitudes del Caribe centroamericano.

Esta variedad sociocultural de la provincia de Limón crea una situación afectada por las actitudes ambiguas con respecto a las diferencias raciales y los estereotipos. A pesar de que durante la segunda mitad del siglo XX ha cobrado impulso un reajuste social, económico y político de los habitantes de la zona como parte de un proceso de cooptación que ha vivido el país, aun así sigue existiendo una discriminación de clase y de etnia, encubierta por estas actitudes de ambigüedad (Bozzoli 1996: 134).

La cultura antillana de América Central, ha estado relacionada con las transnacionales estadounidenses que operan desde mediados del siglo XIX en la costa Caribe centroamericana. Se trasladaron con todo su arsenal cultural y se fueron adaptando a las nuevas circunstancias. La migración desde las Antillas a las costas continentales es determinada, en parte, por la caída de la plantación esclavista, causada fundamentalmente por el tránsito del capitalismo mercantil al capitalismo industrial. Tenemos entonces que los antillanos abandonan "sus" países, no solamente por las dificultades económicas, sino que también, y esto es muy importante, con el fin de "hacer uso" y reafirmar su recién obtenida libertad. Así los antillanos llegan al país para trabajar en el ferrocarril y en las plantaciones de banano, que ya por esa época se habían constituido en un fuerte polo de atracción de mano de obra de todas las latitudes.

El negro que en un principio fue esclavizado y obligado a migrar, actualmente se enfrenta a nuevas realidades, nuevas circunstancias sociales, ambientales y de poder. Esto lo obliga a sobrevivir en una búsqueda constante de identidad al habérsele cercenado la propia, por lo 
que recrea nuevos mitos, nuevas relaciones en un proceso de recreación de sus componentes euroafricanos (Moreno 1977: 31). Al instalarse para residir en las repúblicas continentales, debe readaptar su manera de vivir y de estar, pues deben recrear y aprender de las nuevas circunstancias en un Estado Nacional al que llegan intempestivamente. Así como se construyeron focos de resistencia en la época esclavista, en la nueva época republicana aparecerán organizaciones que cumplirán un papel similar ante esas nuevas condiciones.

En el Caribe y en Limón la Iglesia se convierte en una organización comunitaria donde los miembros se apoyan mutuamente. En el caso de Limón hemos determinado elementos que se oponen al control social y político de las autoridades del Estado-Nación. Basta recordar que en determinado momento de la historia la Iglesia protestante y en especial la Metodista, apoyó a los esclavos en su lucha emancipadora (Lampe 1997:49-58). En este sentido el inglés funciona como idioma que une y la escuela de inglés se convierte en un centro ideológico donde se mantiene y se transforma la identidad. La iglesia fomenta el idioma inglés como una herramienta de superación y resistencia, por familiaridad, cohesión religiosa, de raza, espiritualidad e identidad.

Lo que hay que tener claro, es que buena parte de los inmigrantes negros a la costa de la provincia de Limón, habían creado una identidad relacionada con el Real Imperio Británico y un sistema de vida que lo sustentaba, dentro del cual cabe que el gobierno inglés subvencione la Iglesia y su escuela. Se puede probar que realmente existió intermediación de su Majestad en beneficio de los súbditos, en varios casos, incluso el Gobierno de Costa Rica ordenó un censo de todos los súbditos británicos residentes en la jurisdicción de Limón (Murillo 1999:191). Para cambiar la influencia inglesa y sus valores en la zona, el Estado costarricense inicia ciertas prácticas que incluyen la nueva escuela, la pública, que quiere transformar esos valores.

En la actualidad el papel importante de los líderes religiosos poco ha cambiado en cuanto a su liderazgo en la comunidad negra. La escuela de inglés funcionó como centro ideológico, donde se mantenía y se transformaba la identidad, aunque posteriormente perdió su status preferencial. Así, la importancia de esta escuela varió sustancialmente, liderando la escolaridad nacional, con sus programas y su idioma oficial, el español. El inglés, un inglés criollo, funciona como idioma que une; la iglesia lo fomenta por familiaridad, cohesión religiosa, de raza, espiritualidad 
e identidad. Sin embargo ante la envestida oficial del Estado, con sus escuelas, medios de comunicación y otras prácticas, el inglés va perdiendo espacios. Como reductos del idioma se mantienen el hogar y la Iglesia, es dentro de ésta última que actúan los coros que funcionan en varios sentidos. La funcionalidad y la misión de la iglesia y de la escuela, pareciera ser, pierde su importancia y cede espacio a nuevas realidades de poder.

\section{LA IGLESIA Y LA ESCUELA UNIDOS POR EL BIEN COMÚN}

Paralelamente, con la llegada de afro caribeños, se instalaron en Puerto Limón diferentes misiones religiosas de cuño protestante. La Iglesia Bautista, con seis miembros, fue la que primero se organizó a partir del 2 de diciembre de 1888 y ya al año siguiente abrió sus puertas a su feligresía en Cahuita, Nine Miles, Matina, Porvenir, Guácimo y Turrialba. En 1890 la Iglesia Bautista inició sus homilías en español. Su primer templo en Puerto Limón funcionó en el centro de la ciudad en terrenos donados por Minor Keith; allí funcionó durante aproximadamente diez años hasta que el Dr. Pánfilo Valverde donó los terrenos donde actualmente funciona en la parte norte de la ciudad.

La Iglesia Metodista inicia su funcionamiento en 1894 en Pacuarito, de donde se expande a través de la Comarca. En 1896 se abre la Iglesia Anglicana (Episcopal) en Puerto Limón; su templo funcionó hasta 1958 en el costado oeste del actual estadio de baseball. Por su lado, la Iglesia Adventista del Séptimo Día inicia su obra evangelizadora en 1902 en Pacuarito con 26 miembros; de allí expande sus operaciones a través de toda la Comarca.

La obra misionera de los protestantes se expandió a las principales comunidades instaladas a lo largo de la vía férrea que conectaba Puerto Limón con la capital, San José (Turrialba, Siquirres, Pacuarito, Matina, 25 Millas ( hoy Bataán), 28 Millas, Zent, Estrada, Cuba Creek, Nine Miles; Línea Vieja (Cairo, Germania, Guácimo) y hacia el sur de la Comarca en pueblos como Valle de la Estrella, Penshurt, Bonifacio, San Andrés, Beverly, Filadelfia, Kent, Old Harbour y Cahuita. Todas ellas eran algunas de las comunidades que se beneficiaron con la llegada de misioneros protestantes. Y decimos que se beneficiaron porque los protestantes 
inculcaban en la población valores más allá de la fe cristiana, más allá de los valores de identidad. Hablar de protestantismo era no solamente hablar de la iglesia y su misión, era también hablar de educación, de arte, de cultura en general. La Iglesia era sinónimo de educación, sinónimo de cultura.

La mayoría de esos poblados eran habitados por antillanos anglo parlantes y protestantes, por lo que los cultos, al igual que en Puerto Limón, se celebraban y aún hoy en día continúan celebrándose en inglés, pero también en español. Tal situación, a su vez, no impedía a que la población "local" compartiera de actividades propias de los afro antillanos como era el caso del deporte, por ejemplo el críquet, muy arraigado en Gran Bretaña y sus colonias. Muchos "españoles" participaban activamente de algunas actividades culturales ya que a las escuelas de inglés también asistían alumnos "blancos", hijos de los "españoles" (spanish men) o "paña" como son llamados por parte de los negros. Poco a poco, las misiones protestantes iniciaron sus misas en español con lo que gran cantidad de personas, no precisamente de origen antillano, empezaron asistir a los templos protestantes. El antillano y la Iglesia protestante, inician así un largo y tortuoso recorrido en su afán de construir, en nuevas realidades, una nueva identidad.

\section{LA INCURSIÓN DEL ESTADO EN EL CARIBE DE COSTA RICA}

Una de las preocupaciones más grandes para el Estado costarricense, desde los albores de su vida independiente, ha sido el apoyo a la educación. Sin embargo, por la concentración poblacional, era en la parte central del país en donde se ubicaban la inmensa mayoría de escuelas y lógicamente eran a esas escuelas a las que se les otorgaba la mayor cantidad de recursos (Muñoz, 2002:215-217). En cuanto más alejado de la llamada Meseta Central, menos eran las posibilidades de acceder a la educación, no solamente por su escaso presupuesto y cobertura, sino también por las difíciles condiciones de salubridad que tenían que afrontar los maestros destacados en la periferia.

En el caso del Caribe costarricense, el Estado primero mantuvo la región en abandono total para luego ceder su soberanía a las empresas extranjeras en lo que se ha dado en denominar como situación de enclave. Se construyo un Estado paralelo en donde las compañías extranjeras eran las que imponían sus condiciones al Estado costarricense prácticamente en todos los 


\section{ay) concaso

Indexaciones: Repositorio de Revistas UCR, DIALNET, Latindex, REDALYC Directorio y recolector de recursos digitales del Ministerio de Cultura de España, Directory of Open Access Journals. Diálogos Revista Electrónica de Historia ISSN 1409- 469X. Número especial 2008. Dirección web: http://historia.fcs.ucr.ac.cr/dialogos.htm

ámbitos de la vida cotidiana. Es por eso que, para el caso que nos ocupa, las empresas extranjeras propiciaron la llegada de misiones religiosas afines al poder imperial, en este caso a la Corona Británica. A su vez, estas misiones religiosas, en la mayoría de las veces, fueron utilizadas para afianzar el poder colonial a través de la fe y la instrucción.

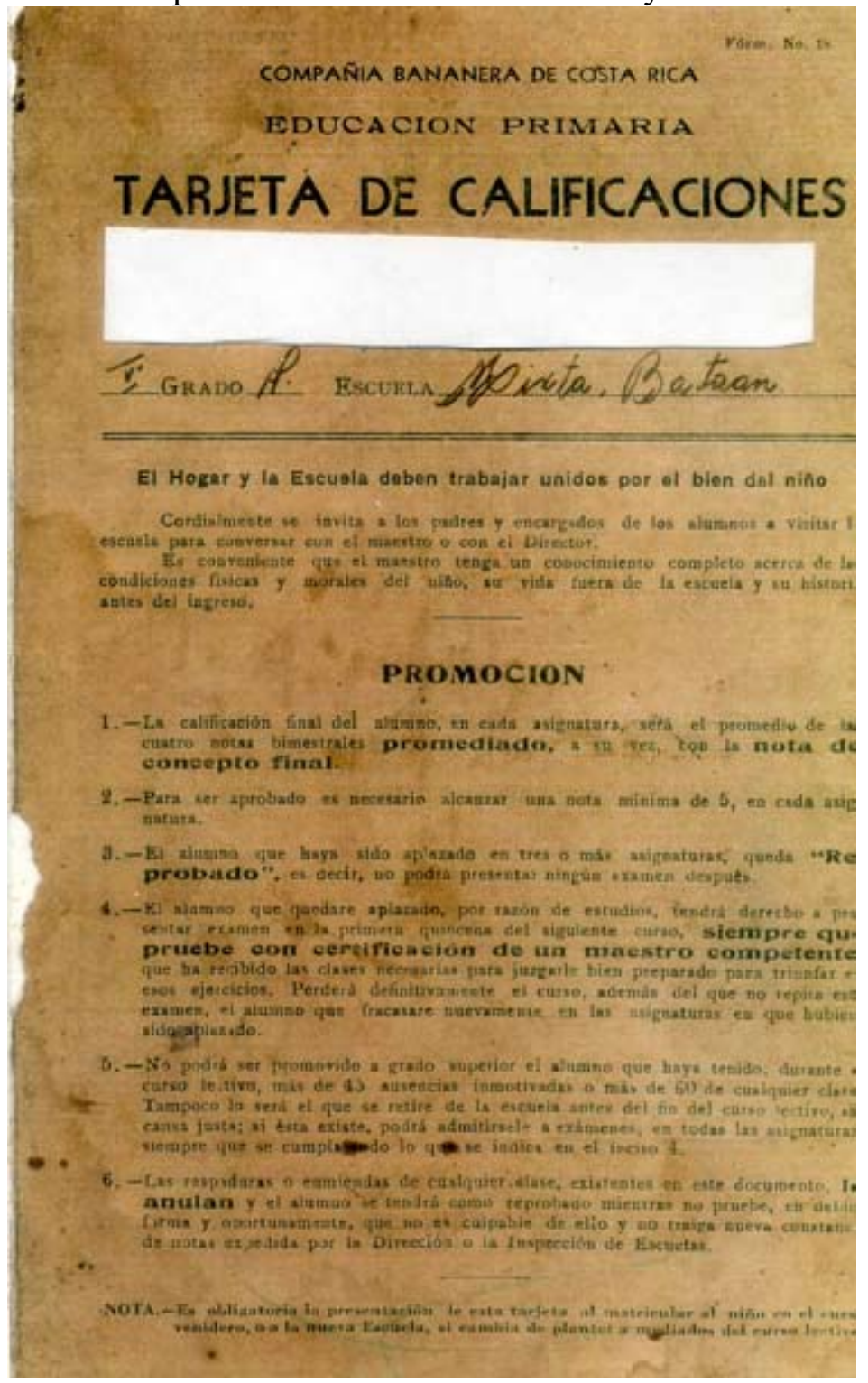

Portada de una Tarjeta de Calificaciones de un niño de la Escuela Mixta de Bataán en el año 1951. Nótese en el encabezado que la Escuela es tutelada por la Compañía Bananera de Costa Rica, antes United Fruit Company. 
Constatamos así que, a pesar que la inmigración antillana hacia el Caribe costarricense se había incrementado notoriamente, era poco lo que el Estado hacía por responder a las necesidades de la población antillana, al menos en el ámbito de la educación. Es mas, el Estado costarricense era poco o nada lo que hacía por su propia población en esta región del país.

Durante gran parte del siglo XIX la Comarca de Limón no contó con servicios de educación pública de ningún tipo. No fue sino hasta 1877 durante la Administración de Tomás Guardia, según acuerdo \# 5 del 13 de febrero de 1877, que se crea, con significativo retraso, la Escuela de varones de Limón que por largo tiempo fue la única escuela oficial en toda la Comarca. En las justificaciones para la apertura de aquella primera escuela pública (estatal), se esgrimían razones como que

"El Limón progresa en todo sentido...que en tal virtud, es llegada la hora de establecer una escuela pública en la cabecera de aquella Comarca, necesidad tanto mas imperiosa cuanto que, con motivo de la afluencia de extranjeros, se ha generalizado el idioma inglés, y es conveniente que la mera generación, en aquella importante sección de la República, aprenda con perfección y de toda preferencia el Castellano" (ANCR, 28488).

En las postrimerías del siglo XIX el Estado trata de enmendar ese vacío. En los documentos oficiales de la Secretaría de Instrucción y los Informes de ésta al Congreso de la República, por primera vez se hace referencia a las escuelas públicas de Limón en el año 1900. Al terminar 1899 habían 325 escuelas en toda la República, de las cuales tan solo dos funcionaban en Puerto Limón, una de varones y otra de niñas con 34 estudiantes cada una (ANCR: 25.135). Para 1903 en Limón se tenían 38 escolares varones y 46 niñas (ANCR:21.124; 113-114). 


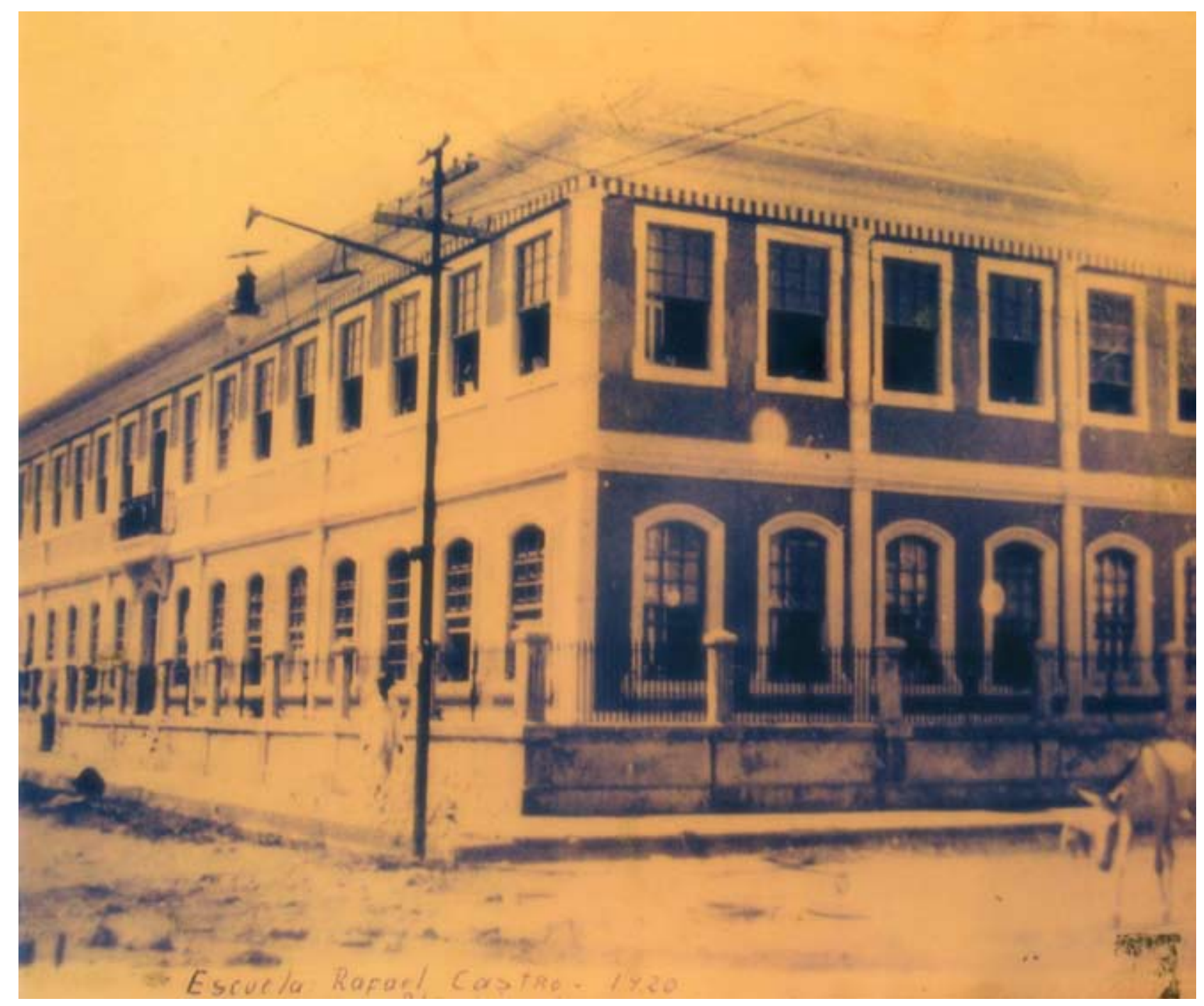

Escuela Rafael Iglesias Castro de Puerto Limón. Vista del costado suroeste. Año 1920.

Nuevamente se tiene noticias de las escuelas de Limón en el Informe de la misma Secretaría de Instrucción referente al año 1912 donde se menciona del funcionamiento de 383 escuelas en toda la República, 13 de las cuales se encontraban en Limón con 946 estudiantes, de los cuales, 500 eran costarricenses y 446 extranjeros (ANCR, 21146:110). Recordemos que en los documentos oficiales del Estado costarricense el término extranjero se refería, en el caso de Limón, a los ciudadanos de origen jamaiquino o antillano, de donde intuimos que los 446 
extranjeros que estudiaban en las escuelas públicas de Limón eran niños hijos de ciudadanos afro antillanos.

\section{CUADRO \# 1. PUERTO LIMON. ESCUELAS PÚBLICAS. 1877-1940.}

\begin{tabular}{|c|c|c|c|c|c|}
\hline$\underline{\mathrm{ANNO}}$ & $\begin{array}{l}\text { CANTIDAD } \\
\text { ESCUELAS }\end{array}$ & $\underline{\text { VARONES }}$ & $\underline{\text { NIÑAS }}$ & TOTAL & FUENTE \\
\hline 1877 & 1 & & & & \\
\hline 1896 & 2 & 30 & 45 & 75 & ANCR 21.111 \\
\hline 1899 & 2 & 34 & 34 & 68 & ANCR 25.135 \\
\hline 1903 & 2 & 38 & 46 & 84 & ANCR 21.124 \\
\hline 1905 & 2 & 44 & 36 & 80 & ANCR 20.893 \\
\hline 1911 & 12 & & & 943 & ANCR21.146 \\
\hline 1912 & 13 & & & 946 & ANCR21.146 \\
\hline 1913 & 15 & & & 875 & ANCR21.075 \\
\hline 1914 & 14 & & & 866 & ANCR21.130 \\
\hline 1922 & 5 & & & 584 & ANCR21.090 \\
\hline 1926 & 9 & 428 & 362 & 790 & ANCR21.123 \\
\hline 1927 & 8 & & & 695 & ANCR21.072 \\
\hline 1940 & 12 & 314 & 286 & 600 & ANCR21.083 \\
\hline
\end{tabular}

Recordemos que fue precisamente a través de la instrucción que el Estado costarricense forjo la "nacionalización" de la región del Caribe, no sin antes topar con serias dificultades en ese intento "nacionalizador", entre otras tantas razones por la negativa de los padres de enviar a sus hijos a una escuela "extranjera" y por la intensa movilidad de las poblaciones que constantemente debían emigrar en la búsqueda de mejores condiciones de vida. Llega un momento en que el Estado costarricense obliga a los padres de familia de origen antillano a enviar a sus hijos a la escuela en español, en detrimento de las escuelas en inglés. 


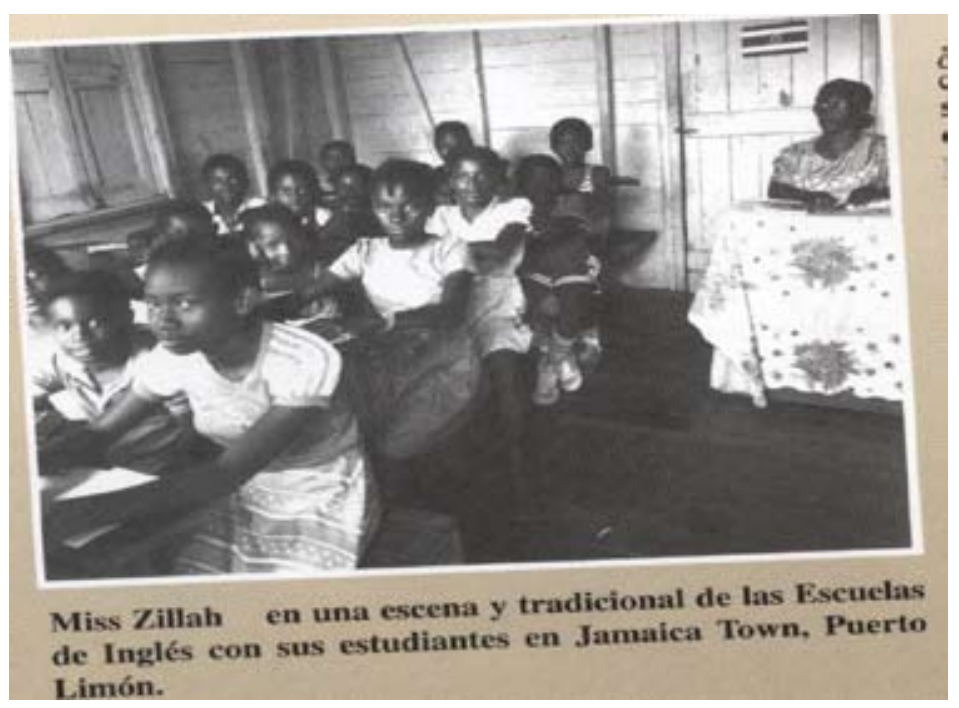

Miss Zillah y su grupo en la Escuela de inglés. Tomada de la revista Limón Roots.

\section{LA MISIÓN IDEOLOGICA DE LAS ESCUELAS PARROQUIALES(1890-1940).}

El Estado-nación, un concepto de la Ilustración, es un aparato jurídico de cohesión social. El mismo tiene un instrumental institucional que busca homogeneizar, unificar y centralizar. Y también reprimir. La idea liberal que se tiene en los países latinoamericanos de una cultura para todos, desplaza y margina; ignora y destruye. Ese carácter dominante fue percibido y manejado por los diferentes grupos de inmigrantes (Martín Barbero 1991), que buscaron como convivir con eso. Uno de los casos más interesantes es el de los negros de la América continental provenientes del África Occidental vía Caribe.

La dimensión simbólica de su lucha tiene una tradición que viene desde su pasado africano y se inserta en el Caribe, manteniendo características peculiares. Articula una protesta simbólica y reutiliza elementos combinados euroafricanos. El siglo XX en la historia de los inmigrantes negros ha sido toda una lucha por hacer comunicable su memoria y su experiencia. 
Al seno de las iglesias protestantes o no católicas se observa un fenómeno hasta ahora poco estudiado y que tiene que ver con esa experiencia. Es lo que en Limón se conoce como la Escuela de Inglés, pero relacionada con la actividad espiritual y cultural. Esta escuela cumple un papel muy activo en la educación y la transmisión de valores culturales y lingüísticos. Reproducen programas impartidos en Jamaica e Inglaterra; las diferentes denominaciones religiosas y la Asociación Universal para el Mejoramiento del Negro (UNIA), fueron estimuladas y apoyadas por las transnacionales, cada una defendiendo sus propios intereses.

Con el apoyo de las escuelas en inglés, la Compañía Bananera estimulaba la inmigración de jóvenes negros pues necesitaba gente para cubrir los puestos en sus oficinas, hospitales y bancos, ya que la documentación se manejó en inglés y este idioma se usó para la comunicación con los jerarcas de las fincas. Por su lado, las iglesias protestantes han tenido gran influencia en la población negra, una buena parte de los cuales son originarios de Jamaica (Castillo 2000:69-70). A su vez, la UNIA acepta como parte de su identidad la característica del inglés como idioma unificador de la negritud. Además, los jamaiquinos eran inmigrantes de paso que volverían a su país de origen, al menos era lo prometido.

En los años treinta del siglo XX la educación impulsada por el Estado costarricense se estabiliza en Limón, pero es a partir de la década de los cincuenta que se asienta con mayor éxito. Reprime el uso del inglés, incluso a través de multas a quienes hablaran en la escuela pública en inglés criollo o inglés. La alfabetización propuesta por las iglesias y la alfabetización propuesta por el Estado de Costa Rica tiene puntos divergentes. Con la primera reforma liberal de la educación se busca alfabetizar para liberar al hombre, incluso de la Iglesia. Solo el hombre civilizado a través de la lectura puede ser libre. Por su lado, con el protestantismo desde el inicio de este movimiento religioso se busca alfabetizar como requisito para la evangelización, pues la salvación eterna se da a través de la palabra escrita en la Biblia. Dentro de este proyecto de salvación cabe la escuela como formadora de fe.

Para entender mejor sobre el origen y funcionamiento de las escuelas, que bajo diferentes auspicios funcionaron en el Caribe de Costa Rica a finales del siglo XIX, trataremos de explicar las particularidades de las escuelas dominicales, escuelas de inglés y escuelas parroquiales. 
Así, las escuelas dominicales funcionaron y aún lo hacen, al amparo de las iglesias, protestantes en su mayoría, que impulsaban el aprendizaje de la lengua, inglesa en su momento, con el fin de que los hijos de los feligreses pudieran luego estudiar las sagradas escrituras. Los hijos de los feligreses, antes o luego de los cultos religiosos de los domingos se quedaban para ahondar en el conocimiento de la lengua, la doctrina y otros menesteres considerados como indispensables en su momento.

Por su parte las escuelas de inglés, aunque una gran parte funcionaron bajo el paraguas de alguna iglesia de cuño protestante, en gran número lo hizo de manera independiente en donde el maestro o maestra combinaba sus actividades académicas con administrativas. Por lo general el maestro o maestra pertenecían a alguna de esas comunidades religiosas. Actualmente estas escuelas continúan funcionando, aunque con menor auge.

En Puerto Limón y en diferentes puntos de la Comarca, fueron los pastores protestantes los que incursionaron en el campo de la educación, inclusive antes de la acometida del Estado. La escuela parroquial impulsa no solo el conocimiento de la lengua inglesa y las sagradas escrituras, sino que va más allá con la implementación de materias como historia, geografía, aritmética, oficios varios, artes y deportes; se impulsa la formación integral del educando.

\section{GENESIS DE LA ESCUELA PROTESTANTE}

La escuela dominical (Sabbath schooll) es una Institución que se difundió en las iglesias evangélicas desde comienzos del siglo XIX y se conserva hasta hoy ( Guerra, 2006:61). Vemos entonces, que los aportes más importantes del protestantismo en Costa Rica, amén de su impulso a la formación teológica, fue la formación cívica, educativa y cultural en general de la juventud caribeña, a través de las escuelas parroquiales que tuvieron su origen a finales del siglo XIX y principios del siglo XX en la costa del Caribe de Costa Rica. Dichas escuelas se desarrollaron por toda la geografía de la costa caribeña de nuestro país, inclusive en los lugares más inhóspitos e inaccesibles de la región en donde el Estado costarricense brillaba por su ausencia. 
Ya en las Memorias de la Secretaría de Instrucción de 1890 se da cuenta del acuerdo \#647 de dicha cartera, tomado el 14 de abril de ese año, en donde

"se comisiona al Reverendo Joshua A. Sobey, pastor protestante de Limón, para contratar un maestro jamaiqueño para la dirección de la escuela pública (sic.) de aquel puerto" (ANCR, 20.960: 14).

La mencionada institución no era otra que la Escuela de la First Baptist Church que recién había abierto sus puertas en Puerto Limón y que tenía de huésped al Reverendo de Montego Bay, Jamaica, Joshua Sobey que había sido enviado a Limón por la Jamaica Baptist Missionary Society en 1887 (www.ctclimon.org ) . En el mismo Informe, sin entrar en detalles, también por primera vez se menciona el funcionamiento en Puerto Limón de las escuelas mixtas San Marcos, Bautista y Católica. Es precisamente el Reverendo Joshua Sobey el que impulsaría la apertura de escuelas en toda La Línea y la costa al sur de Limón, tal como lo hizo en Cahuita en 1905 (Palmer, 2000:95).

La apertura de escuelas en inglés con el auspicio de las iglesias protestantes no siempre fue vista con buenos ojos por el Estado costarricense y sus emisarios. Al contrario, muchas escuelas en inglés eran clausuradas bajo cualquier pretexto, entre otros, porque se esgrimía la obligatoriedad de asistir a la escuela pública, que obvio era, se impartía en español. Tal fue el caso de las escuelas que cobijaba la Iglesia Metodista. Luego de que los Reverendos Pitt y Jacob obtuvieran en 1899 los respectivos permisos de funcionamiento por parte de la Secretaría de Instrucción, sus escuelas se vieron obligadas a cerrar sus puertas ante el acoso y persecución de los oficiales estatales (V Gospel Extravaganza, 2004: 11). Muchas escuelas funcionaban por espacios de tiempo reducidos, mientras que otras lo hacían por periodos más prolongados. Tal fue el caso de la escuela de la Iglesia Metodista, fundada y dirigida por Jessie Wright Pitt, que funcionó desde la década de 1930 hasta inicios de la década de 1970, reabierta nuevamente en 1982 y que actualmente, aunque sin autorización gubernamental, continua prestando sus servicios a la comunidad limonense. 
El cierre de estas escuelas era acompañado de una política de persecución no solamente contra los dirigentes religiosos y escolares, sino que también incluía a las familias antillanas. Las familias, según testimonios recopilados, en muchas ocasiones debían esconder a sus hijos para que no fueran obligados, a menudo a la fuerza, para asistir a las escuelas públicas (Anglin, Mattis, 2005).

Para el $1^{\circ}$. de mayo de 1906 en el Informe al Congreso de la Secretaría de Instrucción Pública, por primera vez en los documentos de dicha instancia se hace mención a la existencia de una importante cantidad de estudiantes de las escuelas parroquiales de la Comarca de Limón. Así, en el informe, aunque no precisa el número exacto de las escuelas, advierte que

"hay un gran número de escuelas privadas á donde reciben educación más de doscientos niños” (ANCR, 20893).

Las cifras que se ofrecen en algunos informes oficiales a menudo carecen de sustento pues para entonces la cantidad de alumnos que asistían a las escuelas parroquiales no eran objeto de la estadística oficial en virtud del desinterés estatal por dichas escuelas. Las escuelas, a su vez, carecían de datos estadísticos y archivos que respaldaran los datos que, como el anterior, brindaba la Secretaría de Instrucción en su informe anual.

Para esta época, con su política de nacionalización, el Estado ya se preocupaba por facilitar el acceso a las escuelas públicas de los niños jamaiquinos, así como también se denotaba una marcada preocupación por acercarse a dicha población. En el Informe del Inspector de Educación para la Comarca de Limón, el señor Carlos Johanning, se señalaba que,

"por disposición de la Secretaría y tomando en cuenta las necesidades especiales de este lugar, se estableció una clase diaria de inglés para el personal de las escuelas de esta ciudad a cargo del señor Clausen”(ANCR 21146).

Esta interesante y estratégica iniciativa del Estado costarricense por involucrar y aproximar a los maestros a la comunidad antillana fracasó debido al poco interés mostrado por 
el personal docente destacado en Puerto Limón. Vemos así que, a pesar del interés de quienes dirigían la Secretaría de Instrucción por enmendar la situación, son los mismos educadores quienes ya por aquella época mostraban su reticencia al intercambio cultural, problema que aún se denota en algunos sectores de la población meseteña.

En 1927, el inspector de escuelas de la provincia de Limón, Ramón Céspedes, en uno de los más completos informes que se tiene noticia de aquella época, esgrimía algunas consideraciones que él consideraba indispensables para afianzar el poder del Estado en la región. Algunas de sus apreciaciones sobre la vida e idiosincrasia de los pobladores de esta región aún hoy en día continúan siendo válidas, veamos porqué:

"Al visitar los distintos lugares de la zona atlántica, se tiene la impresión de que se viaja por un país distinto al nuestro: se habla otro idioma, se practica otra religión, hay diferencia en los cultivos, en la alimentación, en los trajes, en las habitaciones; los jornales se pagan en dólares, las festividades son otras; las medidas corrientes también son distintas. Las poblaciones se componen en su gran mayoría de jamaiquinos que imponen sus usos y costumbres...Las personas que conocen esas situaciones y que se interesan por los asuntos de bien general, hablan de la conveniencia de nacionalizar la zona atlántica. Esa obra de nacionalización corresponde a la Escuela” (ANCR 21.123).

La posición expresada por el Sr. Céspedes denota una clara visión ideológica de quienes en ese momento ostentaban las riendas del Estado nacional. Es importante señalar que la región del Caribe costarricense y sus habitantes, eran vistos desde la óptica del poder ejercido desde el centro, de tal manera que a menudo se apreciaba cierto desdén y hasta desprecio en las políticas del Estado costarricense, apreciaciones que se emitían desde la capital en una típica dimensión de relaciones de poder centro-periferia, condición que aún perdura en las mentes de la población meseteña, cuando se habla de la región Caribe y de sus pobladores.

Recordemos que, según el Censo de Población de 1927, en la provincia de Limón vivían 32 mil 278 personas, de los que 18003 eran de raza negra (Censo 1927: 90); del total 20688 eran alfabetizadas, 62 semianalfabetos y 6091 del todo analfabetos; 5320 eran niños de 
0 a 8 años (Censo 1927: 44-45). Estas cifras, en términos relativos, nos muestra que el nivel de alfabetización en la región del Caribe era elevado e inclusive en algunas zonas como Puerto Limón, superior a la media nacional, ello en razón de que la mayoría de su población era de raza negra ya alfabetizada o que bien recibía instrucción en la escuela de inglés o la escuela parroquial. Así, mientras en el país el analfabetismo llegaba casi al 23 \% de la población, en la provincia de Limón era de 18,7 \%, cifras que son más contundentes cuando extraemos los datos referentes al cantón central de Limón con una clara predominación de población de raza negra y en donde el analfabetismo no superaba el $12 \%$ (Censo 1927:44-53). Todo esto nos indica la importancia que jugaba la instrucción en la población limonense y el papel de la iglesia protestante en la formación de la población local. Otro ejemplo sobre la alfabetización existente en Limón de inicios del siglo XX fue el número de periódicos que circulaban tanto en inglés como en español o en ambos idiomas a la vez.

Para 1940 se brinda la información gubernamental más detallada que se conoce sobre el funcionamiento de las escuelas parroquiales de Limón centro. Se nota que la Iglesia Católica, que desde ya hacia mucho tiempo atrás había perdido el monopolio y control sobre la educación, estaba en franca desventaja numérica con respecto a la cantidad de estudiantes matriculados en sus escuelas, tal como lo vemos en el cuadro \# 2. Del total de niños que asistían a la escuela, que eran 600 estudiantes, 463 lo hacían en las escuelas que funcionaban bajo el paraguas de alguna iglesia protestante. A su vez, a las escuelas católicas de toda la Comarca asistían a clases tan solo 137 niños en Limón centro y 11 niños en Little Hope. 


\section{CUADRO \# 2. PUERTO LIMON. ESCUELAS PARROQUIALES. AÑO 1940.}

\begin{tabular}{|c|c|c|c|c|c|c|}
\hline ESCUELA & $\underline{\text { SECCIONES }}$ & $\underline{\text { VARONES }}$ & $\underline{\text { NIÑAS }}$ & TOTAL & $\begin{array}{l}\text { C A N T. } \\
\text { MAEST }\end{array}$ & NIVEL \\
\hline Escuela de la & 7 & 19 & 8 & 27 & 2 & $1-\mathrm{VII}$ \\
\hline E s c u e l a & 7 & 24 & 22 & 46 & 2 & K-VI \\
\hline $\begin{array}{l}\text { S a lv a ti o n } \\
\text { Army }\end{array}$ & 6 & 36 & 34 & 70 & 2 & $\mathrm{~K}-\mathrm{VI}$ \\
\hline Católica & 7 & 55 & 82 & 137 & 3 & $\mathrm{~K}-\mathrm{VI}$ \\
\hline Alpha Cottage & 6 & 45 & 36 & 81 & 2 & I-VI \\
\hline $\begin{array}{l}\text { Protestante } \\
\text { San Marcos }\end{array}$ & 5 & 29 & 11 & 40 & 1 & $\mathrm{I}-\mathrm{V}$ \\
\hline Bautista & 4 & 23 & 21 & 44 & 1 & K-III \\
\hline $\begin{array}{l}\text { Virgen Maria } \\
\text { (Anglicana) }\end{array}$ & 3 & 34 & 27 & 61 & 1 & K-VI \\
\hline $\begin{array}{l}\text { Adventista del } \\
7^{0} \text { Día }\end{array}$ & 7 & 23 & 20 & 43 & 2 & K-VII \\
\hline Masónica & 2 & 8 & 8 & 16 & 1 & I-II \\
\hline Saint Albani*s & 3 & 18 & 17 & 35 & 2 & $\mathrm{~K}-\mathrm{II}$ \\
\hline TOTAL & 57 & 314 & 286 & 600 & 19 & \\
\hline
\end{tabular}

Fuente: Ministerio de Educación Pública. Informe 1941. (ANCR 21.083).

Asimismo, podemos darnos cuenta de la cobertura de las iglesias protestantes cuando en el mismo informe de la Secretaria de Educación correspondiente a 1940 se menciona del funcionamiento de las escuelas Metodista en Estrada, Brooklin Day de Siquirres y Little Hope (Católica) de Matina. Importante dato es que aún en 1940, cuando se supone que el Estado no solamente había incursionado, sino que debía de tener el control de la educación, la mayoría de los niños asistían a escuelas no oficiales. De los 1241 alumnos matriculados en ese momento en las escuelas oficiales y privadas en la Comarca de Limón, 765 alumnos estudiaban en los diferentes niveles de las escuelas parroquiales o privadas de la Comarca (ANCR 21.083). 
Los datos anteriormente señalados, demuestran de una u otra manera, que los padres de familia daban gran importancia a la educación de sus hijos, en momentos en que la población limonense, sin distingos de raza o credo religioso, habían llegado al Caribe costarricense a forjarse un mejor futuro en las construcciones del ferrocarril, del puerto o en las plantaciones bananeras. Vale destacar que si bien es cierto que desde la óptica del Estado nacional (católico, apostólico y romano) la educación era vista en términos de superación personal y un medio para "civilizar" y homogenizar desde el poder central, otra era la perspectiva desde el protestantismo, ya que la forma de ver la educación era desde otra dimensión, pues se consideraba y aún se le considera como vía de acceso a la lectura bíblica y como instrumento de salvación.

\section{ADMINISTRACIÓN DE LAS ESCUELAS PARROQUIALES}

Las escuelas parroquiales funcionan en el Caribe costarricense desde fines del siglo XIX cuando las iglesias San Marcos, Católica y la Primera Iglesia Bautista amparan la creación de escuelas parroquiales en Puerto Limón (ANCR, 20.960: 14). En la mayoría de los casos estas escuelas funcionaban bajo el paraguas de las diferentes denominaciones religiosas, protestantes, las más, muchas de las cuales, además, tenían un carácter familiar, pues a menudo los encargados eran los familiares cercanos al Pastor. Tal practica, en algunos casos, se mantiene aún en la actualidad.

La administración de estas escuelas recaía generalmente en el pastor de la iglesia que en muchas de las ocasiones era pastor y maestro a la vez. En otros casos la esposa del pastor ofrecía de maestra. En muchas ocasiones las labores de pastor las combinaba con la docencia y la administración. Estas labores eran muy sencillas ya que se limitaban al cobro de la matrícula, organización de los cursos, elaboración de horarios y buscar empleo para sus graduandos en las empresas de la zona. En aquellas escuelas más grandes era la Iglesia la que contrataba los maestros y por lo tanto era el staff de dicha iglesia la que se encargaba de todos los aspectos administrativos liberando al maestro de esta labor (Mattis, 2005). Algunas de estas prácticas se 
mantienen en la actualidad

\section{LAS ESCUELAS PARTICULARES}

Pero también hubo casos de las escuelas de inglés que funcionaron bajo la égida de algún mentor particular. Este tipo de escuelas proliferaron en el pasado y continúan funcionando en la actualidad, siendo su objetivo primordial la enseñanza de la lengua inglesa, sin más; obviamente funcionaron y aún funcionan sin los requerimientos estatales, sin que ello sea un impedimento para que gran cantidad de familias (no solamente familias negras) aún el día de hoy, continúen enviando sus hijos a dichas escuelas.

\section{PERFIL DEL MAESTRO}

Los maestros por lo general eran ciudadanos de Jamaica. El maestro era una persona altamente calificada, con un nivel de instrucción muy por encima del nivel educativo del maestro costarricense, ello a pesar de que el instructor jamaicano, en la mayoría de los casos, no había concluido estudios superiores. El maestro era persona respetada por todos y con un gran poder en su comunidad; era un ciudadano ejemplar para todos. Los maestros comúnmente impartían lecciones en todos los niveles, desde primer grado y hasta sexto grado, allí donde los había. Sus lecciones eran impartidas en inglés salvo raras excepciones que se impartían en inglés y español a la vez.

\section{EL CURRÍCULO DE LAS ESCUELAS PARROQUIALES}

El currículo de las escuelas parroquiales generalmente era una fiel copia del currículo que se implementaba por aquella época en Jamaica, fuertemente influenciada por el sistema educativo británico. Las escuelas parroquiales no se limitaban a la enseñanza del idioma inglés, básico para la comprensión de las sagradas escrituras, sino que extendía su enseñanza a la aritmética, la historia y geografía de Inglaterra y sus colonias.

En años superiores algunas escuelas ofrecían cursos de comercio, contabilidad, 
taquigrafia, música y en algunos casos aprendian a tocar algún instrumento...Algunas escuelas incluían educación para el hogar y mecanografia para las mujeres y agriculturay comercio para los hombres...Las escuelas diferían unas de otras, dependiendo del aspecto que enfatizaban y de la preparación del maestro. La mayoría centraba sus actividades en torno a la enseñanza de la aritmética, gramática, música y religión (Anglin, 1981:14).

Recordemos que entre el proyecto colonial y el proyecto protestante no existía diferencia alguna, política que era prolongada en la escuela de molde protestante. De allí que los curricula escolares que se implementaban en Jamaica, y que era el mismo que se desarrollaba en Limón, promovía la britanización de sus colonias y sus pobladores.

Los antillanos se sentían british citizens y estaban orgullosos de ello. Habia una gran lealtad a la Reina y a la Corona Británica. Los antillanos en Costa Rica no se sentían costarricenses y despreciaban todo lo tico (Anglin, 2005).

Los libros de texto se traían de Jamaica o Inglaterra y todos los alumnos estaban obligados a adquirir sus textos en el comercio local. En Puerto Limón los libros de texto eran distribuidos por la tienda de Jack Orane, negocio que funcionó hasta la década de 1960 contiguo a la antigua Proveedora, en la avenida principal de la ciudad.

\section{PLANTA FÍSICA}

La planta física de estas escuelas por lo general eran los mismos salones que servían de templo. Estos salones eran casas de madera de la zona y en los que, en muchas ocasiones, se brindaban lecciones de varios niveles a la vez... En otros casos, las escuelas operaban en las casas de los maestros o en los corredores de las casas donde vivían estos maestros, lo cual daba motivo para llamar a éstas, escuelas de corredor (Castillo, 2002:179). 


\section{METODOLOGÍAS Y TÉCNICAS DE ENSEÑANZA}

Era una enseñanza personalizada y memorística; los estudiantes con su libro de texto se acercaban donde el maestro a leerle y éste les corregía. Todos los niños sostenían entre sus piernas una pizarrita (slate) para escribir y que luego se borraba fácilmente. Asimismo, todos los días se practicaba las tablas de multiplicación. Este era un ejercicio obligatorio pues se dedicaba mucho tiempo a las matemáticas. Obligatoriamente, todos los días por la mañana se recitaba el Our Father. Por otro, antes de inicio de lecciones y durante varios minutos se hacían ejercicios físicos.

\section{SISTEMA DE EVALUACIÓN Y PROMOCIÓN}

El sistema de evaluación era diario, continuo. Se trabajaba con un libro de textos que generalmente se importaba de Inglaterra o de Jamaica. Todos los textos eran en british english. Todos los días había una lectura nueva que el niño debía leer de pie ante el maestro. También se asignaban vocablos para deletrear.

En matemáticas los textos eran variados con diferentes excercices, dependiendo de cómo se iba avanzando en la materia y en el nivel. Todos los días se repasaban las tablas de multiplicación.

Había periodos de examen, los cuales eran muy rigurosos; los llamados dictation examen eran una tortura para todos los niños. Estos, de pie, frente al maestro debían de rendir cuenta de lo que sabían; era lo que se llamaba back to back, face to face. Por cada cuatro errores que cometía el alumno, este recibía un fajazo y luego debía de escribir varias páginas con las palabras donde se cometieron los errores. Todos los días el alumno obligatoriamente debía hacer un summary lection. (Mattis, 2005). 


\section{VALORES}

Se inculcaba y practicaba el respeto, la solidaridad, la hermandad y la nobleza; disciplina y puntualidad era indisoluble; los buenos modales, la higiene, el aseo, la buena presentación de cada persona era importantísimo. Se puede decir que muchos de estos valores eran heredados de la cultura británica, pero en su mayoría eran postulados de profundo arraigo y tradición africanos.

\section{FESTIVIDADES.}

En la Escuela y en la Iglesia se preparaban con anticipación para ciertas celebraciones que se organizaban con tal de participar activamente. Así, había grupos de canto, de danza, de teatro, grupos para recitar.

Las actividades más grandes y hermosas eran para Navidad, Año Nuevo y el Harvest Day. El Harvest Day se celebraba una vez al año y cada Iglesia celebraba su Harvest; por lo general la actividad se desarrollaba de viernes a domingo. El Harvest Day era una gran fiesta donde había de todo, como actividades culturales y deportivas; todo con el fin de recolectar fondos para la Iglesia: así, los finqueros llevaban cacao, cocos, naranjas, yuca, ñame, jackfruit, akee; los panaderos sus panes y pastelería; en fin, todo mundo aportaba algo. Ya desde el viernes se empezaba a llevar cosas y a congregarse la gente. El lunes la iglesia ponía todos los productos recolectados a la venta y de tal manera recaudar fondos para la Iglesia. Entre las diferentes iglesias protestantes había una gran solidaridad y ayudaban a celebrar el Harvest en cada iglesia; la actividad se turnaba de una a otra congregación. En la actualidad, aún se mantiene la tradición, aunque con menos fervor.

\section{HARVEST DAY}

(By Mae Reyna Jackson, s/a, p.24.)

"Twas Autumn, and the northwind, low

Among the trees, passed slowly through,

Whispering to the leaves in bright array,

The reapers are coming, it's Harvest Day. 
The corns like nuns in triple gowns,

All trimmed with fringes, silk and brown,

By reapers were gently taken away,

To be loved white temple on Harvest Day.

And hundreds or ripe, round oranges,

Wearing yellow suppressed dresses,

Went rolling, and skipping along the way

To be in the temple on Harvest Day.

Long canes with tassels of pale brown,

Leaning, bending with juice weighed down,

Were all taken away to decorate,

The windows, the columns, the temple gate.

Coconuts, lemons and pumpkins,

Bananas, yams and ripe plantains,

Papaya, cassava and peppers gay,

Were at the temple on Harvest Day.

Upon the table richly spread

Were jellies, cakes, large buns and bread,

Cookies and muffins in pink and blue trays,

Half crowded the temple on Harvest Day.

And resting on the altar high,

Were marigold and roses shy,

The chrysantimums and hibiscus red,

Gazed at the Pastor when prayer was said.

The when the church with gifts was graced, 
The people came, some dressed in lace,

And they sang hen they saw the grand display.

We thank Thee, O Lord, for Harvest Day.

\section{LAS ESCUELAS PARROQUIALES DE HOY}

Actualmente funcionan en Puerto Limón, de manera oficial y extraoficial varias escuelas, ligadas de una u otra manera a diferentes denominaciones de cuño protestante, ellas son: Centro Educativo San Marcos, Centro Educativo Adventista, Centro Educativo Bautista del Caribe, Centro Educativo Bilingüe Maranatha, Salvation Army Schooll y Limón Methodist English Schooll. Todos estos centros educativos tienen su génesis en un remoto pasado cuando en el Caribe de Costa Rica se asentaron diferentes denominaciones religiosas de tendencia protestante que, con el pasar del tiempo fueron cerrando sus puertas. Esto se debió, básicamente, por los vaivenes socioeconómicos y políticos del momento. Así, el funcionamiento de iglesias y escuelas dependían de la situación coyuntural tanto interna como externa, tal como fue la conclusión de las obras del ferrocarril y de los puertos, el cierre o traslado de las plantaciones bananeras hacia otras regiones del país o el exterior, por las enfermedades que azotaron las plantaciones de cacao y por último por el cierre de las plantaciones de abacá debido a la conclusión de la Segunda Guerra Mundial, situaciones que provocaron masivas y forzosas migraciones de la población antillana hacia Estados Unidos y Panamá.

En la actualidad muchas de estas denominaciones religiosas tratan de revivir su quehacer cultural alrededor de acciones concretas como la apertura de escuelas, formación de grupos de teatro, coros y danza. Sin embargo, en muchas ocasiones, los líderes religiosos se topan nuevamente con la continua tendencia de la población antillana a emigrar, lo que pone en riesgo los intentos de la iglesia protestante por rescatar sus ancestrales valores culturales. Y es que la constante de emigrar, ya sea por motivos económicos, los más, o por índole familiar, convierte al 
segmento poblacional antillano en un grupo sin arraigo que perennemente está en una constante búsqueda de identidad, independientemente del lugar donde se encuentre.

Muy bien pudiéramos decir, en este caso y en otros parecidos, que la transculturización a que se vio sometido el negro desde su desarraigo del África en el siglo XVI a hoy, aún continua, sean esta su permanencia en la América hispana, las antillas francófonas o Norteamérica.

En la actualidad, una de las particularidades más importantes de la escuela parroquial protestante son los cambios introducidos en los planes de estudio en el marco de regulación de la educación privada impulsada por el Ministerio de Educación Pública. Vemos que en la mayoría de los casos su formación se centra en las materias que impulsa el Ministerio de Educación, con un claro acento hacia las llamadas materias clásicas como matemáticas, química, geografía e historia, en detrimento de las materias religiosas. Otro momento importante es el cambio de orientación y dependencia de la iglesia protestante, que paso de una dependencia político-ideológica y económica de Londres a una dependencia de Estados Unidos, hecho que se denota en su quehacer cotidiano, como por ejemplo, aunque se impulsa la materia de inglés, el énfasis se vuelca al inglés americano con desplazamiento de British English

Lo anterior es reflejo de los cambios geopolíticos mundiales que se manifiestan con mayor intensidad en la última década. Ante esta situación y pese al avasallador dominio de la potencia del norte, tanto la UNIA como ciertos sectores de la iglesia protestante limonense participan de algunas actividades reivindicativas de la población local convirtiéndose en algunos momentos en mediadores y proponentes de iniciativas en concreto. A más de 100 años de su incursión en el Caribe de Costa Rica, la iglesia protestante de Puerto Limón reafirma sus principios y valores que algún día le convirtió en una de las más respetadas instituciones de la región.

En la actualidad continúan funcionando escuelas muy pequeñas, específicamente de las llamadas Sabbath School, con un énfasis más doctrinario y con la estimulación del inglés. En este sentido, la importancia del aprendizaje del inglés dado por esta escuela ha sido reafirmada por el uso de este idioma en el currículo escolar oficial actual. 


\section{CITAS}

\section{FUENTES OFICIALES}

ANCR. Serie Instrucción. Doc. 3774; 1870.

ANCR. Serie Gobernación. Doc. 28488; 14 febrero 1877.

ANCR. Serie Gobernación. Doc.28890, 18 mayo 1884. (Escuela de Nathan Anderson).

ANCR. Serie Instrucción. Doc. 21136; 22 julio 1885.

ANCR. Serie Instrucción. Doc. 21133; 25 mayo 1886.

ANCR. Serie Instrucción. Doc. 21131; 24 junio 1887.

ANCR. Serie Instrucción. Doc. 20960; 1890.

ANCR. Serie Instrucción. Doc. 21129; 1 de mayo 1890.

ANCR. Serie Instrucción. Doc. 21111; 1897.

ANCR. Serie Instrucción. Doc. 21135; 15 junio 1900.

ANCR. Serie Instrucción. Doc. 21124; 16 mayo 1904.

ANCR. Serie Instrucción. Doc. 20893, 1905.

ANCR. Serie Instrucción. Doc. 21132, 1908.

ANCR. Serie Instrucción. Doc. 21134, 1909.

ANCR. Serie Instrucción. Doc. 21074,1911.

ANCR. Serie Instrucción. Doc. 21146, 1912.

ANCR. Serie Instrucción. Doc. 21075, 1913.

ANCR. Serie Instrucción. Doc. 21130, 1914.

ANCR. Serie Educación. Doc. 21090, 1922.

ANCR. Serie Educación. Doc. 21122, 1923.

ANCR. Serie Educación. Doc. 21123, 1926.

ANCR. Serie Educación. Doc. 21072, 1927.

ANCR. Serie Educación. Doc. 21085, 1929.

ANCR. Serie Educación. Doc. 21082, 1937.

ANCR. Serie Educación. Doc. 21083, 1940.

ANCR. Serie Memoria MEP. Doc. 21076, 1950.

ANCR. Serie Memoria Anual MEP. Doc. 21073, 1959.

Censos de Población 1875, 1883, 1892, 1927, 1950. 
(1996) Costa Rica Episcopal Church Anglican Comunion. St. Mark's Church Memory. Port Limon, Costa Rica 1896-1996.

Ministerio de Educación Pública. Informe 1941. (ANCR 21.083).

\section{MONOGRAFIAS}

Anglin, R. (1981) Las escuelas parroquiales de Limón. Mimeo de la Facultad de Educación. San José: Universidad de Costa Rica.

Barbero, Martín (1991) De los medios a las mediaciones. Barcelona: Gustavo Gili, 2a. Edición.

Castillo, D. (2000) Understanding our past in the school experience. En: Revista InterSedes, Vol. I, \# 1, pp. 61-77.

( 2004) Programa de mano. 26 de mayo de 2004, The Black Star Line, Puerto Limón: Limon Negro Cultural and Civic Comité.

Jackson, Mae Reyna. (s/a.) Poems. Puerto Limón: Imp. Excelsior.

Muñoz, Ileana (2002). Educación y Régimen Municipal en Costa Rica. 1821-1882. San José: Editorial de la Universidad de Costa Rica.

\section{FUENTES DE INTERNET}

www.ctclimon.org A sketch of the early history of the First Baptist Church in Costa Rica. Página citada el 24 de mayo de 2008.

\section{ENTREVISTAS}

Anglin, Raymond (2005), Coward, Héctor (2005), Mattis, Jerónimo (2005). 